\title{
Study on the Effect of Different Bed Sills on Flow Structure and Scouring at the Bed of Channel
}

\author{
Alireza Keshavarzi ${ }^{1,2}$, Moslem Sohrabi ${ }^{2}$ \\ ${ }^{1}$ Center for Infrastructure Engineering, Western Sydney University \\ Penrith, Australia \\ A.keshavarzy@westernsydney.edu.au \\ ${ }^{2}$ Water Eng. Department, Shiraz University \\ Shiraz, Iran \\ Moslem.sohrabi@gmail.com
}

\begin{abstract}
Stabilizing the banks and bed of the river is one of the most important problems in river engineering. This importance arises from the scouring of the banks and bed of a river impacting on hydraulic structures and the aquatic environment. Using a bed sill is one way of mitigating bed and bank scouring. Both experimental and numerical techniques were employed to analyse concave, convex and sine bed sills. It was found that a concave bed sill developed vortices at the banks and transferred sediments to the middle of the channel. This caused stability of the channel's centre when compared to the convex bed sill. Such stability leads to the stabilization of banks by creating the maximum depth of scour at the centre of the channel. Since both concave and convex bed sills stabilize only bed or banks, other types of bed sills such as sine shape was also tested in stabilization of both bed and banks. The distance of vortices location from the bank could affect the stability of bed and banks of the channel. The experimental observation confirmed that the maximum and minimum of scouring depth was related to the concave and convex bed sills, respectively.
\end{abstract}

Keywords: River engineering, bed sills, Scour, Experimental model, Numerical model.

\section{Introduction}

One of the major concerns of environmental hydraulic engineers which is very complicated and is not completely well understood is the bed and bank scouring. The problem of the scouring of bed and bank of the river is not only stability problem in natural and artificial channels but also creation of riverine habitat problem for fishes. The most beneficial solution to confront the problem of scouring is using the bed sills.

Some studies for example by [8] and [7] have shown that bed scouring downstream of a linear sill in a hydraulic jump creates maximum scouring hole at the downstream of the linear sill. The maximum scour downstream of large hydraulic structures in rivers was measured in steady and unsteady conditions [9]. Some studies also by [2], [13], [4], [10], [1], and [12] have shown bed scouring around linear bed sill that constructed at right angle to the flow direction under different flow conditions.

An experiment by [3] showed that scouring downstream of bed sill with different distances under high slope, showed a non-linear regression relationship from which maximum depth of scouring could be determined. A comprehensive experimental program by [11] showed that concave pattern bed sill produced minimum bed scouring at the centre of the channel whereas convex pattern bed sill produced minimum bed scouring occurred at the banks. Their results were verified by testing nine different models of bed sills including linear, convex, concave and tilted fixed to the flow direction. The pattern of flow and turbulence structures in a scour hole downstream of a submerged weir was examined by [5].The results showed that flow structure changed near the structure in downstream of submerged weir, a large vortex area and flow reattachment area were also formed. The study by [6] showed that flow regimes over the weir were independent of the sediment size at the bed, and also flow regime could be defined as a function of upstream Froude number and weir height to tail water depth ratio. With regard to the complication in flow structure around other types of bed sill it is essential to focus on both experimental and numerical analysis of flow structure in order to assess the flow patterns and their influences on bed and banks of the channels. As a result, in this study a numerical and experimental research study has been made to evaluate the flow structure at downstream of bed sills. 


\section{Materials and Method}

A set of experimental tests were undertaken in a non-recirculating mobile bed glass flume with length, width and depth of $15 \mathrm{~m}, 0.7 \mathrm{~m}$ and $0.6 \mathrm{~m}$, respectively. The bed of the flume was covered with $120 \mathrm{~mm}$ sand particle with an approximately uniform size of $\mathrm{D}_{50}$ equal to $0.78 \mathrm{~mm}$. Table 1 shows the flow conditions for data set of experiments. Figure 1 , demonstrates the three different types of bed sills. These 3 types include, concave, convex, sine shape bed sill. These bed sills were installed at the bed of the flume to inquire the influence of each type dimension on erosion of bed and banks of the channel. Each experiment was operated for about 18 to 24 hours. Moreover, a digital roughness meter was used to measure the bed scouring in a grid. The water depth inside the flume was controlled by a gate at the end of the flume. Furthermore, measurement of the flow rate and velocities were made by a pre calibrated V-Notch and ADV respectively.

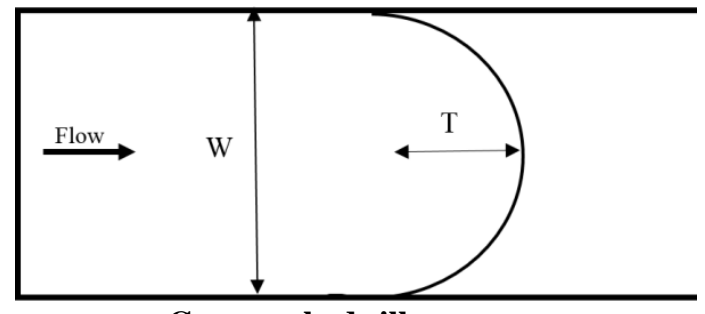

Concave bed sill

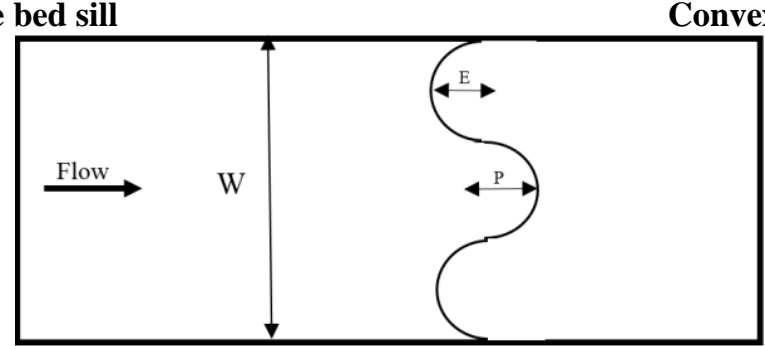

Sine bed sill

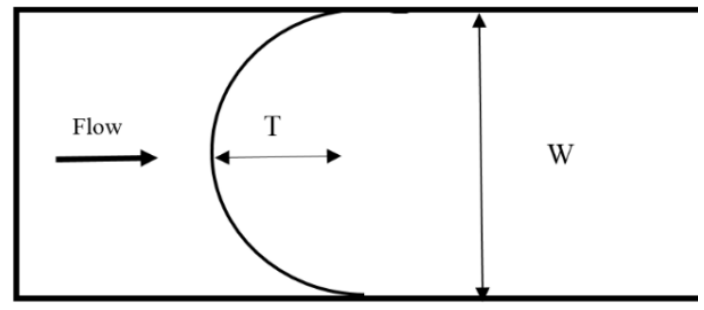

Convex bed sill

Fig. 1: Schematic patterns of all bed sill models.

Table 1: Flow condition in the experimental tests, maximum scouring and cells.

\begin{tabular}{|l|c|c|l|c|}
\hline Model & $\begin{array}{c}\text { Flow } \\
\text { depth(m) }\end{array}$ & $\begin{array}{c}\text { Velocity } \\
(\mathbf{m} / \mathbf{s})\end{array}$ & Cells & $\begin{array}{c}\text { Zs } \\
(\mathbf{m})\end{array}$ \\
\hline $\begin{array}{l}\text { Concave(M3) } \\
\mathrm{T}=0.25\end{array}$ & 0.06 & 0.32 & 299003 & $\mathbf{0 . 0 9 4}$ \\
\hline $\begin{array}{l}\text { Convex(N3) } \\
\mathrm{T}=0.25\end{array}$ & 0.07 & 0.26 & 221790 & $\mathbf{0 . 0 5 2}$ \\
\hline $\begin{array}{l}\text { Sine(A1) } \\
\mathrm{E}=1\end{array}$ & 0.073 & 0.3 & 286666 & $\mathbf{0 . 0 8 3}$ \\
$\mathrm{P}=1$ & & & & \\
\hline
\end{tabular}

\section{Experimental Results}

The concave bed sill is shown to be effective in reducing the erosion of upstream and to stabilize the central section downstream of the bed sill. Therefore, use of concave bed sill has led to the formation of scours at the banks of the channel. In addition, demonstration of the scouring profile in a channel with use of concave bed sill with distances of 0.35 , 0.2 and 0 meters from the wall can be seen in Figure 2. Figure 2 shows that the maximum scouring depth occurs at the banks of the channel while the channel centre has the minimum scouring depth. However, the convex bed sill showed a different flow structure. It is mostly recommended for protection of upstream and banks of downstream of the bed sill. Furthermore, the convex bed sill makes an aquatic habitat at its downstream. It can be observed that the middle part of the channel with convex bed sill has a maximum scouring depth. Some results are shown in Figure 2. The profile of convex bed sill at distances of $0.35,0.2$ and 0 meters from the wall is presented in figure 2. Figure 2 shows that the maximum 
scouring depth occurred at the centre of the channel. By moving away from the banks of the channel, the depth of scouring increases. As mentioned above, the use of concave or convex bed sill may stabilize either centre or banks of a channel. Nonetheless, a combination of concave and convex bed sills referred to as sine bed sill may help to protect both centre and bank of the channel. A sine bed sill is a concave bed sill surrounded by two convex bed sills as shown in figure 1 . The precise results of scouring profile for interspaces of $0.35,0.2$ and 0 meters from the wall of a channel with use of sine bed sill is presented in figure 2. Also it is obvious that the max scouring depth is located at 0.15 meters interval from the walls.

The three dimensional pattern of bed scouring and also the contour lines of scouring at the downstream of the bed sill models are presented in Figures 3. According to the results of the experimental study, it was concluded that not only the pattern of the bed scouring and maximum scouring occurred in very different scheme but the scouring holes were formed at different locations in the bed sill models.

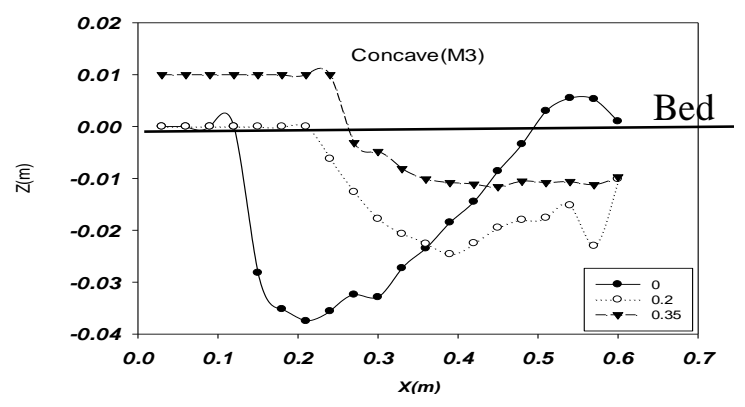

Concave(M3)

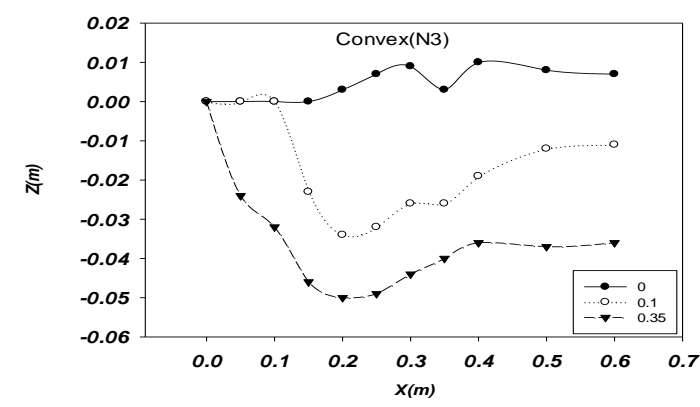

Convex(N3)

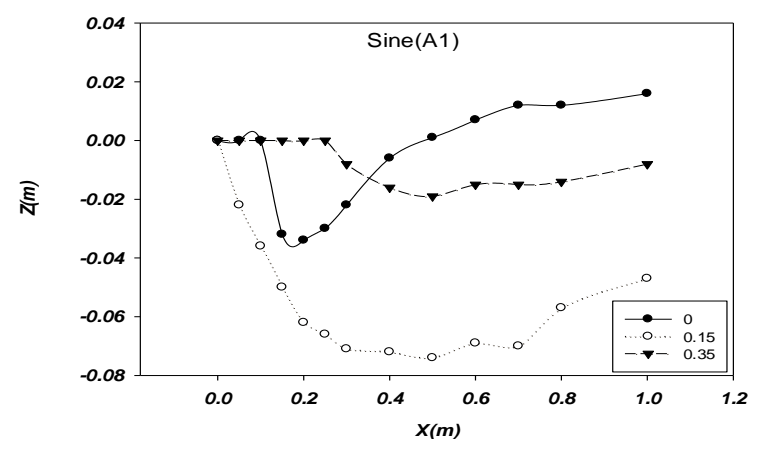

Sine(A1)

Fig. 2: Comparison of bed scouring profile at the centre line, bank and between them for Concave, Convex and Sine shape bed sill models used in the experimental tests. 

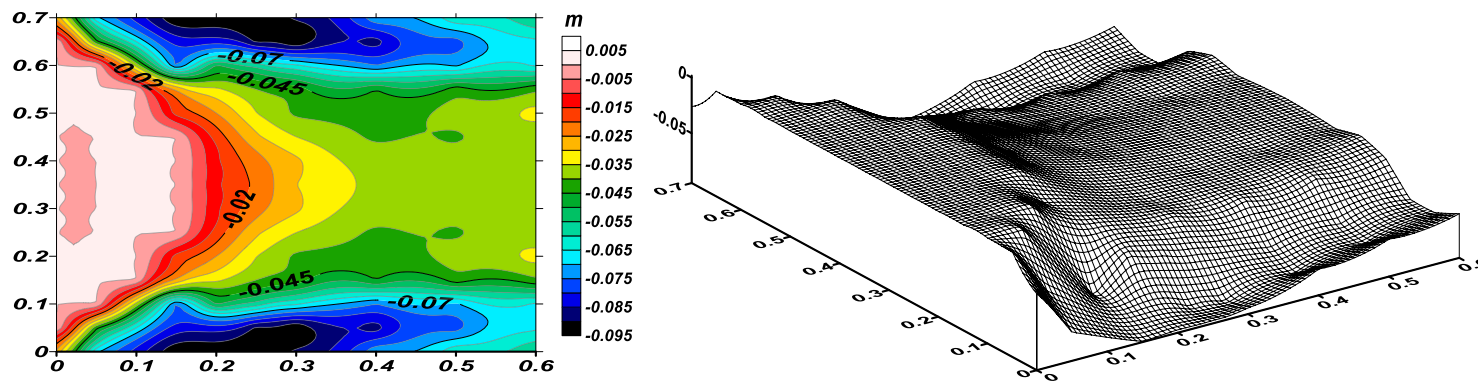

\section{Concave}

Canvex bed sill(N3)
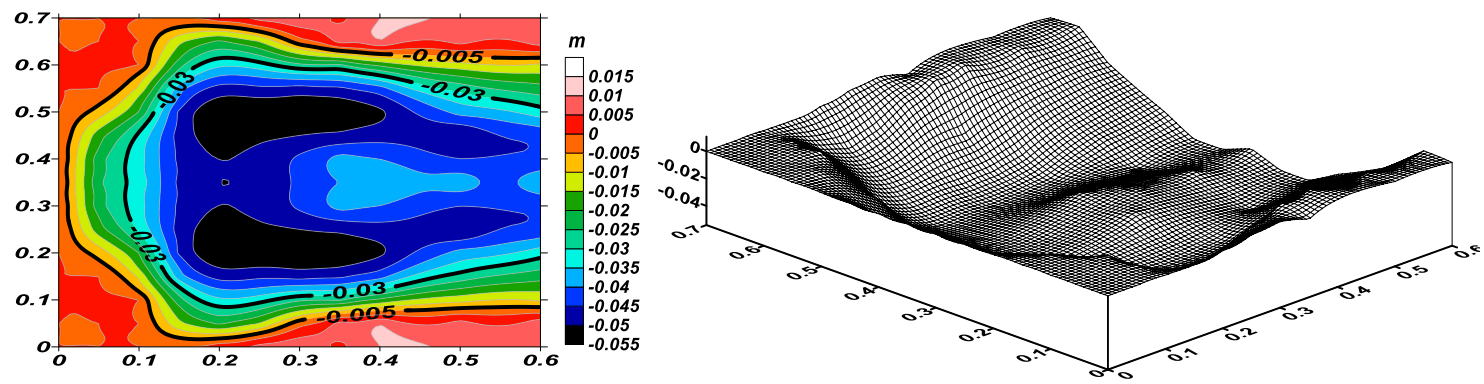

Convex

Sine bed sill(A1)
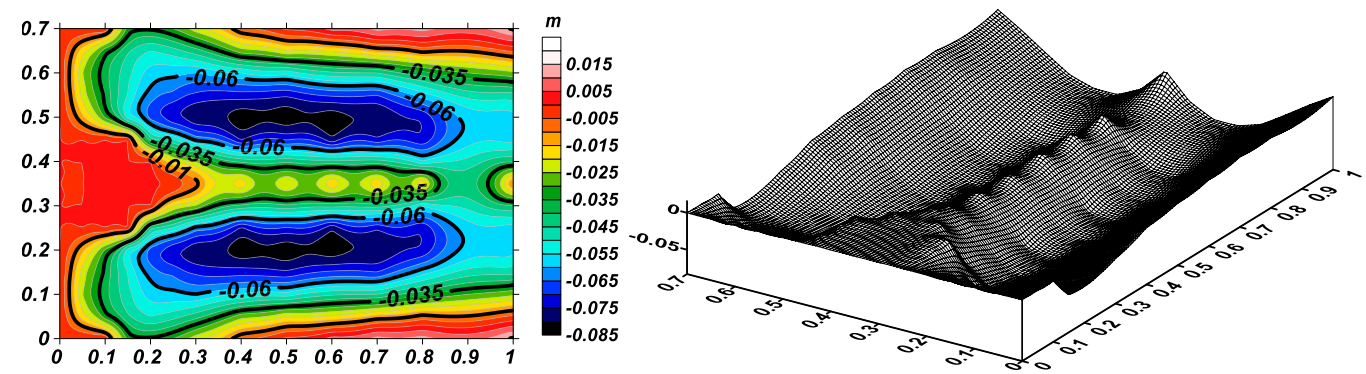

Sine

Fig. 3: Three dimensional and contour lines plots of bed scouring (Test M3, N3 and A1).

\section{Numerical Model}

\subsection{Boundary Conditions And Mesh Study}

In order to prepare flow model geometry, GAMBIT 2.4.6 was used and ANSYS FLUENT was applied to generate the computational mesh. To reduce computing time, only a part of the channel was simulated. Figure 4 illustrates that a structure and unstructured mesh was used in each model with a mesh study used to select the most effective mesh. Boundary conditions include the entrance section, output section, walls and free surface of the boundary. The applied boundary conditions are shown in Figure 5. 


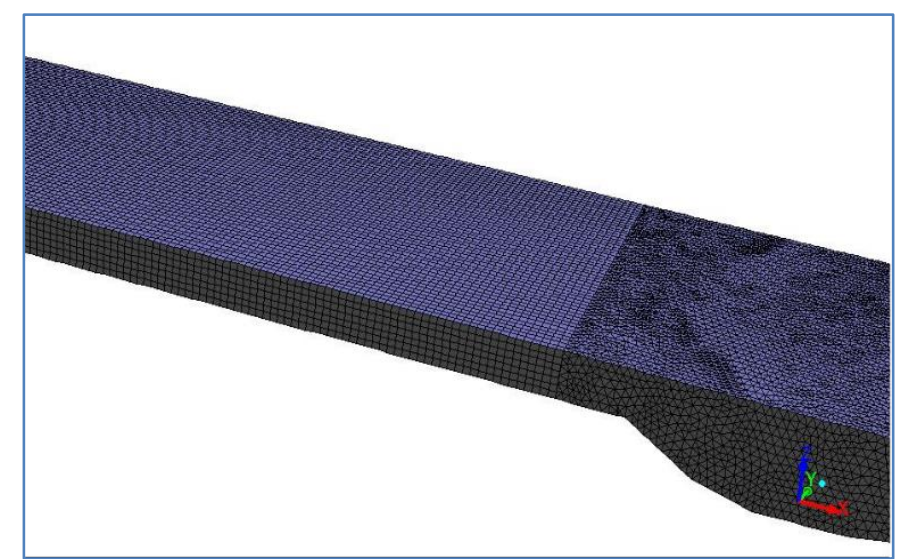

Fig. 4: Grid of simulation domain.

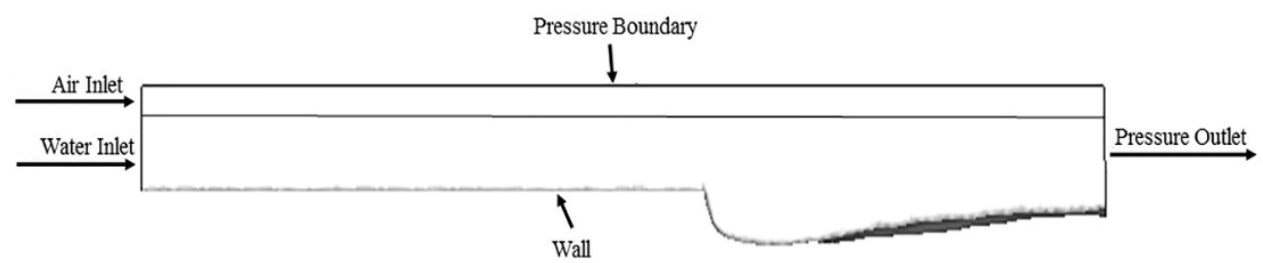

Fig. 5: Boundary condition of simulation domain.

\section{Numerical Results}

In this study, the numerical analysis is done only for one type of concave, Convex and Sine bed sill referred to as M3, $\mathrm{N} 3$ and $\mathrm{A} 1$ in one set of experiments. The concave bed sill protects some sections of the channel by creating vortices at the bank. These vortices transfer the sediment to the middle section of the channel. The flow condition is presented in Table 1 . Figure 6 represents the velocity contours in longitudinal and transverse sections of the channel. Figure 6 shows that by receding from the walls, the negative velocity decreases constantly and this phenomenon transfers the sediments towards the centre of the flume. Moreover, the longitudinal section illustrates a growth in separation zone by approaching from middle to the banks of the channel. Therefore, strong vortices are created at the banks of the channel. This process can increase the erosion in this zone. As it was mentioned earlier, the convex bed sill has an ability to stabilize the banks of the channel by transferring the sediment in the centre with transition of vortices in the middle towards the banks of the channel. The longitudinal section shows that by approaching towards the centre of the channel, the separation zone increases. The sine bed sill can protect bed and banks of a channel from the erosion. The numerical analysis indicates that the maximum scouring depth location is between the wall and centre of the channel. Figure 6 illustrates the longitudinal section of velocity contours. It is proposed that A1 bed sill has a minor separation zone at the banks of the channel which increases by approaching towards the centre zone of the channel. Table 2 shows the errors analysis and the accuracy of the numerical results. The results show that the lowest error for the numerical model is for sine model. 


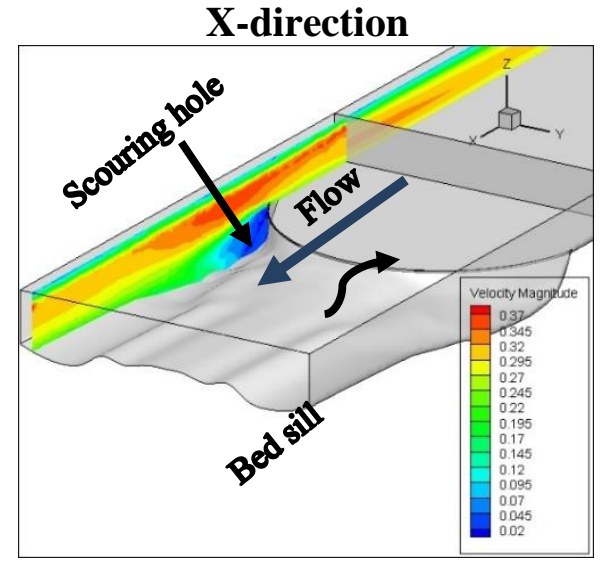

(a) $0.02 \mathrm{~m}$ from wall

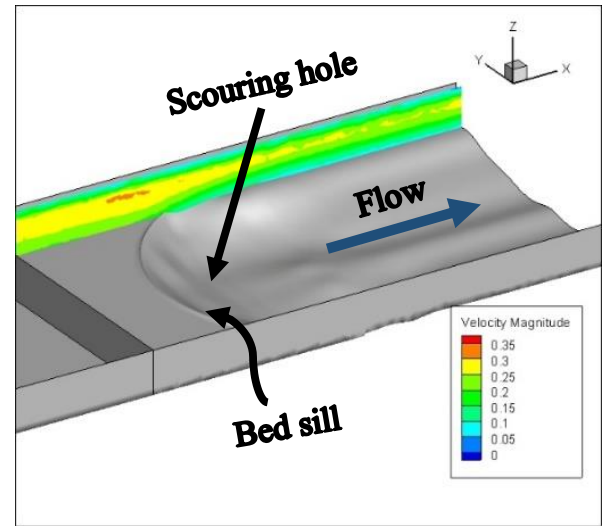

(b) $0.02 \mathrm{~m}$ from wall

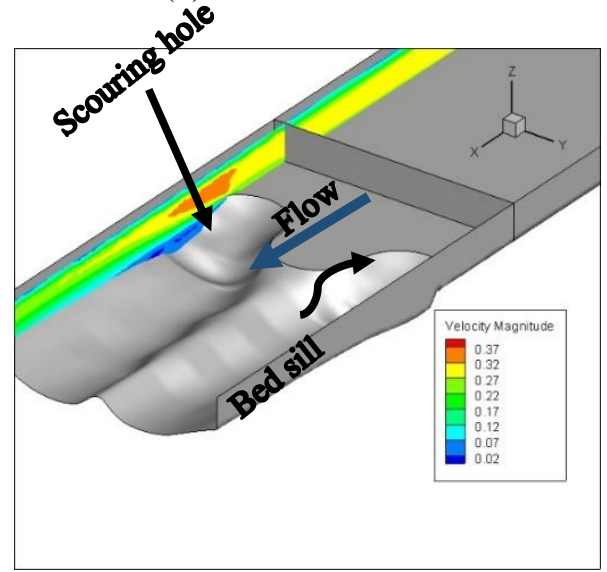

(c) $0.03 \mathrm{~m}$ from wall

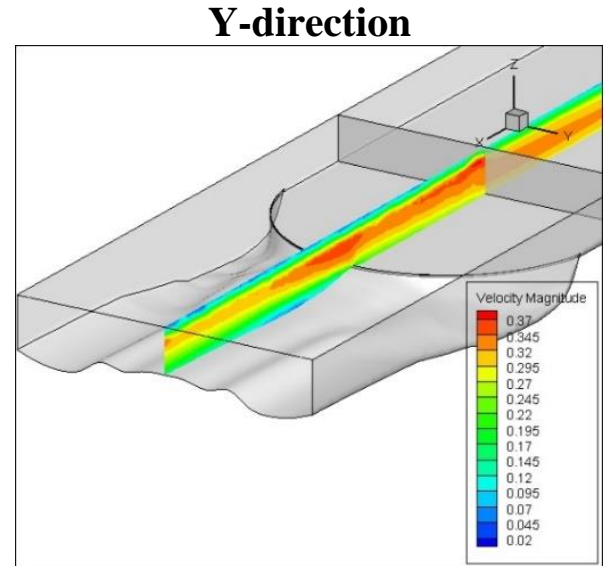

(a) $0.35 \mathrm{~m}$ from wall

\section{Concave}

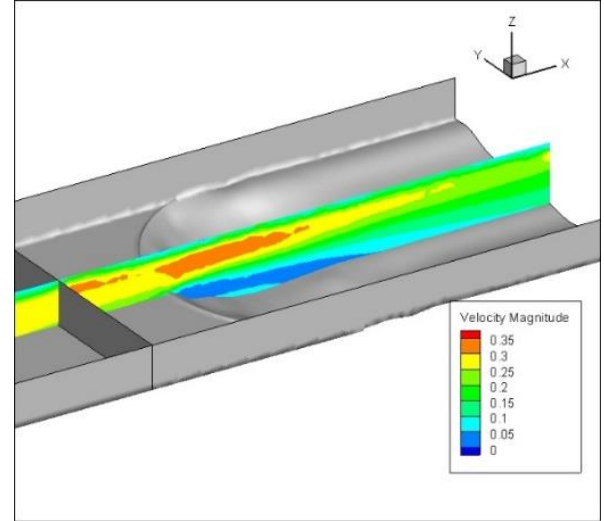

(b) $0.35 \mathrm{~m}$ from wall

Convex

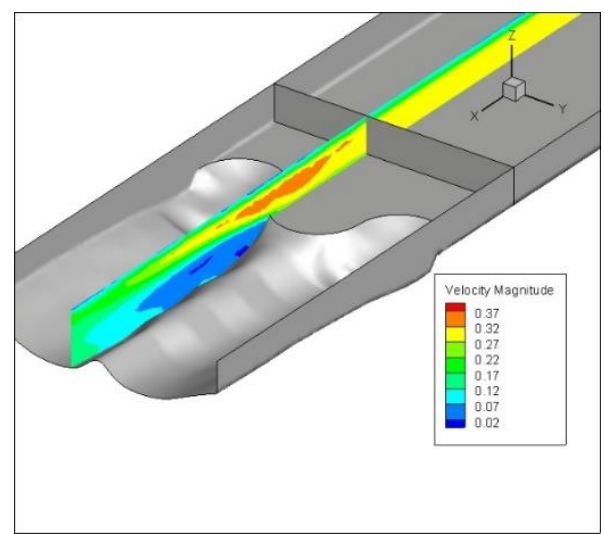

(c) $0.27 \mathrm{~m}$ from wall

Sine

Fig. 6: Contour lines of velocity from side view. 
Table 2: Error Analysis for different models of bed sill.

\begin{tabular}{|l|c|}
\hline Model & Error (\%) \\
\hline Concave(M3) & 8.6 \\
\hline Convex(N3) & 10 \\
\hline Sine(A1) & 5.3 \\
\hline
\end{tabular}

\section{Conclusion}

The concave bed sill creates a major separation zone, scouring and vortices at the banks of the channel. The transfer of sediments to the centre is due to the transportation of bank vortices to this zone. As a result the centre is stabilized. In contrast, the convex bed sill makes the separation zone, scouring and vortices at the middle section of the channel. Stabilization of the sides occurs as a result of transportation of sediments of the banks with movement of vortices towards the walls. However, the sine shape bed sill are recommended to use when it is important to stabilize the banks and centre section simultaneously because the vortices locations vary according to the dimension of the bed sill but the locations of vortices are mainly at both centre and side of the channel. In general, the measurement of bed scouring at the downstream of bed sills showed that the maximum amount of scouring at the bank of the channel occurred by concave bed sills whereas the convex bed sill had the maximum amount of scouring at the centerline of the channel.

\section{References}

[1] N. M. K. N Hassan and R. Narayanan, "Local scour downstream of an apron," J. of Hyd. Eng., ASCE, vol. 111, no. 11, pp. 1371-1385, 1985.

[2] E. Habib, M. Mossa and A. Petrillo, "Scour downstream of hydraulic jump," Modelling, Testing \& Monitoring for Hydro Power Plants Conference, Budapest, Hungary, pp. 561-602, 1994.

[3] G. J. C. M. Hoffmans and K. W. Pilarczyk, "Local scour downstream of hydraulic structures," J. of Hyd. Eng., ASCE, vol. 121, no. 4, pp. 326-340, 1995.

[4] H. N. C. Breusers, "Conformity and time scale in two dimensional local scour," In Proc. Symposium on model and prototype conformity, P: 1-8. Poona: Hydraulic Research Laboratory, 1996.

[5] P. Volkart, J. Tshopp and E. Bisaz, "The effect of sills on river bed, ” Proc. of Int. Symp. on River Mechanics, IAHR, 1, Bangkok, pp. 167-178, 1973.

[6] R. Gaudio and A. Marion, "Time evolution of scouring downstream of bed sills," J. Hyd. Res., vol. 41, no. 3, pp. 271-284, 2003.

[7] M. A. Lenzi, A., Marion, Comiti, F. and R. Gaudio, "Local scouring in low and high gradient streams at bed sills," J. of Hyd. Res., IAHR, vol. 40, no. 6, pp. 731-739, 2002.

[8] M. Ben Meftah and M. Mossa, "Experimental study of the scour hole downstream of bed sills," In M. Greco, A. Carravetta and R. Della Morte (Eds), River Flow, 2004, pp. 585-592.

[9] M. Tregnaghi, "Local scouring at bed sills under steady and unsteady conditions," Ph.D. Thesis, University of Padova, 161, 2008.

[10] C. Chinnarasri and D. Kositgittiwong, "Laboratory study of maximum scour depth downstream of sills," In Proceedings of the ICE-Water Management, vol. 161, no. 5, pp. 267-275, Thomas Telford Ltd, 2008.

[11] A. Keshavarzi and L. Khaje Noori, "Environmental protection stability of river bed and banks using convex, concave, and linear bed sills," Environmental Monitoring and Assessment , vol.17, no.1, pp.621-631, 2010.

[12] D. Guan, B. W. Melville and H. Friedrich, "Flow patterns and turbulence structures in a scour hole downstream of a submerged weir," Journal of Hydraulic Engineering, vol. 140, no.1, pp. 68-76, 2013.

[13] D.Guan, B. Melville and H. Friedrich, "Local scour at submerged weirs in sand-bed channels," Journal of Hydraulic Research, vol. 54, no.2, pp.172-184, 2016. 